\title{
Dynamic Contrast-Enhanced MRI Confirms Rapid And Sustained Improvement Of Rheumatoid Arthritis Induced By Tocilizumab Treatment: An Italian Multicentre Study
}

This article was published in the following Dove Press journal:

Biologics: Targets and Therapy

\section{Marco A Cimmino' \\ Massimiliano Parodi ${ }^{1}$ \\ Francesca Barbieri' \\ Stefano Bombardieri ${ }^{2}$ \\ Giuseppe Zampogna' \\ Annamaria lagnocco ${ }^{3}$ \\ Alberto Batticciotto ${ }^{4}$ \\ Luca Maria Sconfienza $\mathbb{1 D}^{5,6}$ \\ Luigi Sinigaglia $\mathbb{D}^{7}$ \\ Fabrizio De Benedetti $\left(\mathbb{D}^{8}\right.$ \\ Fabiola Atzeni (iD) 9 \\ Piercarlo Sarzi-Puttini ${ }^{10}$ \\ 'Research Laboratory and Academic Division of Clinical Rheumatology, Department of Internal Medicine, University of Genoa, Genoa, Italy; \\ ${ }^{2}$ Rheumatology Unit, Santa Chiara Hospital, University of Pisa, Pisa, Italy; ${ }^{3}$ Academic \\ Rheumatology Centre, Università degli \\ Studi di Torino, Turin, Italy; ${ }^{4}$ Rheumatology \\ Unit ASST-Settelaghi, Ospedale di Circolo- Fondazione Macchi, Varese, Varese, Italy; \\ ${ }^{5}$ IRCCS Istituto Ortopedico Galeazzi, Milan, Italy; ${ }^{6}$ Dipartimento di Scienze Biomediche per la Salute, Università degli Studi di Milano, Milan, Italy; ${ }^{7}$ Rheumatology Unit, G. Pini Hospital, Milan, Italy; ${ }^{8}$ Division of Rheumatology, IRCCS, Bambin Gesù Paediatric Hospital, Rome, Italy; \\ ${ }^{9}$ Rheumatology Unit, University of Messina, Messina, Italy; ${ }^{10}$ Rheumatology Unit, L. Sacco University Hospital, Milan, Italy}

Correspondence: Piercarlo Sarzi-Puttini Reumatology Department, L. Sacco University Hospital, ASST Fatebenefratelli Sacco, Via G.B. Grassi, 74, Milan 20157, Italy Tel +390239042208

Email piercarlo.sarziputtini@gmail.com
Objective: This open-label study evaluated the effects of combined tocilizumab (TCZ) and disease-modifying antirheumatic drugs (DMARDs) on magnetic resonance imaging (MRI) changes in synovial membrane enhancement, bone marrow edema (BME), and erosions in the wrist and hand joints of rheumatoid arthritis (RA) patients inadequately responding to DMARDs alone.

Methods: The efficacy of intravenous TCZ $8 \mathrm{mg} / \mathrm{kg}$ administered every four weeks for 48 weeks was evaluated on six occasions. The primary endpoints were the changes in the extent and degree of wrist synovitis as measured using the RA MRI Score (RAMRIS) and dynamic, gadoliniumenhanced 0.2T MRI (DCE-MRI). A number of different parameters of DCE-MRI were evaluated. Results: Fifty-eight patients were treated, eight of whom (13.8\%) discontinued the study prematurely. The mean RAMRIS significantly decreased after two weeks and the decrease was maintained for up to 48 weeks. By week 4, the mean RAMRIS synovitis score had significantly decreased from baseline $(-0.804 \pm 1.575 ; \mathrm{p}=0.018)$, but not the mean early enhancement $(\mathrm{REE})$ or relative enhancement (RE). However, there were significant decreases in RE at week 24, in REE and $\mathrm{N}_{\text {total }}$ (total number of enhancing voxels)*IRE (initial rate of enhancement) at weeks 12, 24 and 48, and in $\mathrm{N}_{\text {total }} * \mathrm{ME}$ (maximal enhancement) at weeks 24 and 48. Mean BME decreased from baseline to week 48 , and bone erosions did not progress. The patients' clinical parameters significantly improved from baseline until week 48 .

Conclusion: TCZ in combination with DMARDs improved wrist synovitis, BME and clinical parameters, without any progression in bone erosions. The RAMRIS for synovitis rapidly improved from as early as two weeks after the first TCZ infusion. (Funded by F. Hoffmann-La Roche; ACTRACE EudraCT No. 2009 012185-32).

Keywords: tocilizumab, rheumatoid arthritis, wrist, synovitis, low-field MRI, dedicated MRI

There is an increasing need for objective methods to evaluate disease activity and treatment responses in rheumatoid arthritis (RA). In this setting, magnetic resonance imaging (MRI) has proved to be highly sensitive in detecting inflammatory and structural changes, and predicting radiological progression. ${ }^{1}$

Tocilizumab (TCZ) is a recombinant humanised anti-human immunoglobulin IgG1monoclonal antibody against interleukin-6 receptor (IL-6R), a pleiotropic proinflammatory cytokine produced by synovial and endothelial cells in inflamed areas. ${ }^{2}$ 
A number of randomised clinical trials and several long-term follow-up studies have demonstrated that it acts quickly and effectively in RA patients, alone or in combination with other agents, and suggest that it may offer an alternative for patients who have shown an inadequate clinical response to biological or non-biological, disease-modifying anti-rheumatic drugs (DMARDs). ${ }^{3-6}$ It is still debated if the efficacy of TCZ is in part only apparent because of its ability to rapidly inhibit the IL-6 mediated C-reactive protein (CRP) production by the liver. ${ }^{3}$ A more objective method than clinical and laboratory measures could be the evaluation of MRI variables.

The effect of TCZ in RA patients has been previously studied by means of MRI but the original OMERACT Rheumatoid Arthritis MRI Score (applied RAMRIS), which is the preferred method of evaluating MRI in RA, is not always easy to use in the daily clinical practice. ${ }^{7-14}$ In three studies, contrast enhancement was not used and in another it was used but the RAMRIS was mainly evaluated on synovial membrane volumes obtained from the STIR images. $^{7-9,11}$

Synovitis can be measured by MRI without the use of paramagnetic contrast agents or comparing pre- and postcontrast images. In the first case, fat suppression sequences are commonly used which evidence tissues with high water content, such as inflamed synovial membrane and synovial fluid, after exclusion of fat. The advantages of this method are that it is completely non invasive and that the costs, contraindications and the possible, although uncommon, side effects of contrast agents are avoided. The disadvantage is that it is anatomically imprecise because it cannot fully discriminate between synovitis and synovial fluid effusion. As a consequence, i.v. gadolinium is necessary to precisely quantify the volume of inflamed synovial membrane. The most diffused method to assess post-contrast enhancement of the synovial membrane is the RAMRIS, a semiquantitative evaluation of three slices of the wrist and of the metacarpophalangeal joints on a subjective scale between 0 (no enhancement) and one to three (mild, moderate, and severe) by thirds of the presumed maximum volume of enhanced tissue in the synovial compartment. More recently, dynamic, contrastenhanced MRI (DCE-MRI) has been proposed as an objective method to study synovitis by extracting curves from the sequential acquisition of repeated fast T1weighted sequence during intravenous infusion of gadolinium. The focus can be put on a small region of interest (ROI) manually placed in the area with most visual enhancement or on all images in a fully automated approach. The second method should be better for it is more rapid and reproducible, and avoids motion artifacts. It also shows a good correlation with the traditional RAMRIS. $^{15}$

The aims of this study were to evaluate a group of TCZtreated RA patients using extremity-dedicated, contrastenhanced MRI, and assess the usefulness of DCE-MRI using a new computerised technique devised to quantify inflammatory synovial neoangiogenesis and vasodilatation. ${ }^{16}$

\section{Patients And Methods}

\section{Patients}

The study involved adult outpatients with moderate or severe, active RA (disease activity score 28 C-reactive protein $($ DAS-28 CRP) $>3.2$, swollen joint count $\geq 6$, tender joint count $\geq 8$ ) diagnosed on the basis of the 1987 American Rheumatism Association (ACR) criteria. ${ }^{17}$

The other inclusion criteria were a disease duration of at least six months, a poor response to at least three months' previous treatment with a stable dose of nonbiological DMARDs, no previous use of biological treatment, and the inflammatory involvement of at least one wrist at baseline. Patients who had received intra-articular or parenteral corticosteroids in the previous six weeks were excluded, as were those who had received previous treatment with a biological agent.

The patients gave their written informed consent to the study, the protocol of which (EudraCT No. 2009 012185-32) was approved by the Independent Ethics Committees of the 11 participating centres before any study-related procedure was started.

\section{Treatments}

TCZ $8 \mathrm{mg} / \mathrm{kg}$ was intravenously administered by means of a $60 \mathrm{~min}$ infusion every four weeks for a total of 12 infusions. Oral corticosteroids, non-steroidal anti-inflammatory drugs, methotrexate (MTX) or other non-biological DMARDs were continued at a stable dose, unless tapering was required for safety reasons. Up to the maximum recommended doses of additional analgesics could be used to control pain except in the $24 \mathrm{hrs}$ preceding a visit that included the recording of efficacy measures.

\section{Methods}

All of the centres performed MRI using a $0.2 \mathrm{~T}$, extremitydedicated Artoscan unit (Esaote, Genoa, Italy) equipped with a 
permanent magnet and a dedicated, $13 \mathrm{~cm}$ diameter hand and wrist coil. ${ }^{18}$ MRI examinations were performed at baseline and at weeks $2,4,12,24$, and 48 . The imaging technique was standardised during the course of a number of practical meetings. Cushions were used to hold the most severely affected hand (or the dominant hand in the case of symmetrical involvement) in a neutral position with the fingers extended and thumb up. The $120 \mathrm{~mm}$ field of view allowed an evaluation of the carpal bones, proximal metacarpal (MCP) heads, distal radius and ulna. After the first scan, the hand was repositioned to evaluate the MCP and proximal interphalangeal (PIP) joints. Since contrast infusion was performed after the first positioning of the hand, the RAMRIS for synovitis was calculated only for the wrist and not for the metacarpophalangeal joints. The sequences used were: a) pre- and post-enhancement Turbo 3D T1-weighted sequences [TR(repetition time)/ $\mathrm{TE}($ echo time $)=35 / 16 \mathrm{~ms}$; matrix $=192 \times 160$; FOV (field-ofview) $=140 \times 140$; slice thickness $0.8 \mathrm{~mm}$; interslice gap $0 \mathrm{~mm}$ ] recorded in the coronal plane with subsequent reconstruction of the remaining planes; b) coronal and axial STIR sequences $(\mathrm{TR} / \mathrm{TE}=1500 / 24 \mathrm{~ms}$ [coronal] and 2400/24 [axial]; matrix $=192 \times 160$ [coronal] and 192x144 [axial]; FOV=160x160; slice thickness $3 \mathrm{~mm}$ [coronal] and $4 \mathrm{~mm}$ [axial]; interslice gap $0.3 \mathrm{~mm}$ [coronal] and $0.4 \mathrm{~mm}$ [axial]); c) axial Turbo Spin Echo T2-weighted sequences (TR/ $\mathrm{TE}=3520 / 80 \mathrm{~ms}$; matrix $=256 \times 192$, FOV $=150 \times 150$; slice thickness $4 \mathrm{~mm}$; interslice gap $0.4 \mathrm{~mm}$ ); and d) dynamic, contrast-enhanced (DCE) MRI using Spin Echo sequences $(\mathrm{TR} / \mathrm{TE}=100 / 16 \mathrm{~ms}$; matrix=160x128; FOV=170x170; slice thickness $5 \mathrm{~mm}$; interslice gap $0 \mathrm{~mm} ; 3$ slices). After a bolus injection of $0.2 \mathrm{~mL} / \mathrm{kg}$ of Gadolinium-DTPA (diethylenetriamine penta-acetic acid) (Magnevist; Schering, Berlin, Germany), 20 consecutive fast spin-echo images of the wrist were acquired every 18 seconds. The shape of the resulting curve reflects the time-dependent tissue uptake of the contrast: tissues with inflammatory neovascularisation and vasodilation, such as the active synovial membrane, rapidly assume contrast (wash-in phase), and then reach a plateau followed by a washout phase. DCE MRI was used to investigate a ROI in the area of the synovial membrane with the greatest visual enhancement. The rate of early enhancement (REE) per second during the first 55" was calculated using the formula: $\mathrm{REE}_{55}=\left(\mathrm{S}_{55}-\mathrm{S}_{0}\right) /\left(\mathrm{S}_{0} \times 55\right) * 100 \%$, and relative enhancement $(\mathrm{RE})$ at $\mathrm{t}$ seconds was calculated using the formula: $\mathrm{RE}_{\mathrm{t}}=\left(\mathrm{S}_{\mathrm{t}^{-}}\right.$ $\left.\mathrm{S}_{0}\right) / \mathrm{S}_{0} * 100 \%$, where $\mathrm{S}_{0}$ and $\mathrm{S}_{\mathrm{t}}$ are the signal to noise ratios between the signal measured in the ROI and the standard deviation (SD) of the background noise before and $t$ seconds after the injection of the contrast medium. The signal was normalised to an external reference in order to reduce noise. REE is the slope of the curve of contrast uptake tangential to the angle (the steeper the curve, the greater the inflammation), RE indicates the steady state of enhancement.

The images were also evaluated using a novel computeraided technique for the automated processing of the DCE MRI of the whole synovial membrane (Dynamika $^{\circledR}$, ImageAnalysis, UK) after motion correction and filtering. ${ }^{16}$ The area to be investigated was chosen semi-automatically, within a manually outlined ROI drawn quickly around the joint excluding large artefacts such as blood vessels. The signal intensity (SI) vs time curves are extracted from each voxel and automatically assigned to one of four patterns of contrast uptake ("no enhancement", "persistent enhancement", "plateau" or "washout"), which are in effect linear models approximating the SI curves. The "no enhancement" and "persistent enhancement" patterns are typical of tissues unaffected by disease and background, whereas the "plateau" and "washout" patterns are typical of perfused tissues such as inflamed joints or blood vessels. The resulting parameters include maximum enhancement (ME), the \% variation in enhancement from baseline, which is higher in more perfused tissues; the initial rate of enhancement (IRE), the slope of the enhancement curve expressed in \% per second, with the highest values corresponding to the most vascularised tissues; $\mathrm{N}_{\text {total }}$ or the total number of enhancing pixels; $\mathrm{N}_{\text {plateau }}$ or the number of pixels for which the corresponding curves reach the intensity plateau; $\mathrm{N}_{\text {washout }}$ or the number of pixels reaching the washout phase; and $\mathrm{N}_{\text {total }}$ IRE and $\mathrm{N}_{\text {total }}$ *ME, which are composite parameters that reflect the volume and degree of inflammation.

Antero-posterior radiographs of the hands and wrists were obtained at baseline and after 48 weeks, and evaluated centrally at the Genoa centre using the total modified Sharp score (TMSS). All the MRI images were read in the same centre; in particular the STIR images underwent standardisation of the look-up-table to improve contrast.

The primary efficacy endpoints of the study were: i) the extent and degree of wrist synovitis at week 4 as measured using the Rheumatoid Arthritis MRI Score (RAMRIS); and ii) the degree of synovitis at week 4 quantified on the basis of the REE and RE of dynamic, gadolinium-enhanced MRI of the wrist. The secondary efficacy endpoints were the MRI findings at all time points, radiographic changes in the hands, and the clinical and laboratory evaluations usually performed in RA patients. 


\section{Clinical Efficacy}

Disease activity was assessed at each study visit using the DAS 28, a composite of 28 tender joint counts, 28 swollen joint counts, CRP levels, and the patients' visual analogue scale assessment of disease activity. The HAQ disability index was also calculated. The percentage of patients with a DAS 28-based response according to EULAR (20) was recorded.

\section{Statistics}

A sample size of 70 patients had $90 \%$ power to detect a mean difference of 0.9 in RAMRIS for synovitis between baseline and week 4, assuming a SD of 2 and using a paired $t$-test with a 0.017 two-sided significance level, considering the multiplicity of statistical test performed. Efficacy and safety were analysed in the intent-to-treat (ITT) population (i.e. all of the subjects who received at least one dose of treatment). The primary efficacy endpoints were also evaluated in the per-protocol (PP) population (i.e. all of the patients in the ITT population without major protocol violations). A paired $t$-test was used to evaluate the changes in the primary endpoints from baseline to week 4, with Bonferroni correction because of the multiplicity of tests. The Bonferroni correction was considered adequate despite of dependence of outcomes as the more conservative approach, taking into account the explorative nature of the analysis. The changes in the efficacy measures from baseline to any post-baseline time point were evaluated using a repeated ANOVA model. The original data were rank transformed when not normally distributed. The last observation carried forward (LOCF) method was used in the case of missing post-baseline data.

\section{Results}

Fifty-eight RA patients (87.9\% Caucasian; 77.6\% female; mean age $51.5 \pm 13.0$ years; mean disease duration $9.2 \pm 9.1$ years) were recruited at the 11 study centres. The most frequent RA treatments were methotrexate (44 patients, $75.9 \%$ ) and prednisone (27 patients, $46.6 \%$ ). Eight patients $(13.8 \%)$ discontinued the study prematurely, and 43 (74.1\%) were included in the PP population.

Treatment with TCZ was associated with a rapid and progressive improvement in disease activity. There was a significant decrease from baseline in mean DAS-28 CRP levels and the HAQ disability index after just two weeks of treatment, and this was maintained until the end of the study. The mean changes in DAS-28 CRP and HAQ from baseline to the end of the study were respectively $-3.07 \pm$ 1.27 and $-0.67 \pm 0.09$. A good response based on DAS-28 ACR criteria (i.e. a score of $<3.2$ with an improvement from baseline of $>1.2$ ) was observed in $71.6 \%$ of the patients at week 24 , and in $77.3 \%$ at week 48 (Figure 1).

Table 1 shows the results of the primary efficacy endpoints in the ITT population. By week 4, there was a significant decrease from baseline in the mean RAMRIS for wrist synovitis $(p=0.018)$, whereas mean REE and RE did not significantly change. The results in the PP population were consistent with those of the ITT analysis.

In the ANOVA model, the decrease from baseline in mean wrist RAMRIS was significant as early as two weeks after the start of treatment, and this was maintained until the end of the study. The improvement in REE was slower and did not start until week 12, and the decrease in RE was significant only after 24 weeks. The decrease in the RAMRIS for synovitis was similar in all of the individual wrist joints (data not shown). The improvement in MRI measures constantly increased at every time point.

Among the MRI parameters measured using Dynamika ${ }^{\circledR}$ software (Table 2), $\mathrm{N}_{\text {wash-out }}$ and $\mathrm{N}_{\text {total }}$ *IRE significantly decreased from baseline by week 12, whereas $\mathrm{ME}$, $\mathrm{N}_{\text {total }}$ *IRE and $\mathrm{N}_{\text {total }} * \mathrm{ME}$ decreased by week 24 . By week 48 , there was a statistically significant decrease in mean IRE, ME, $\mathrm{N}_{\text {total }}, \mathrm{N}_{\text {plateau }}, \mathrm{N}_{\text {wash-out }}, \mathrm{N}_{\text {total }}$ *IRE and $\mathrm{N}_{\text {total }} * \mathrm{ME}$. Figure 2 shows the changes in $\mathrm{ME}$ in an individual patient.

Figure 3 shows the RAMRIS for bone marrow edema (BME) and erosion. The mean aggregate BME score (wrist +MCP sites) significantly decreased from baseline to week 24 (mean change $-6.70 \pm 10.98 ; \mathrm{p}=0.002$ ) and week 48 (mean change $-8.30 \pm 13.06 ; \mathrm{p}=0.001$ ). Similarly, the mean number of bones with BME progressively decreased from $7.91 \pm 6.27$ at baseline to $4.88 \pm 5.29$ at week $48(\mathrm{p}<0.0001)$. Figure 4 shows the evolution of BME during TCZ treatment

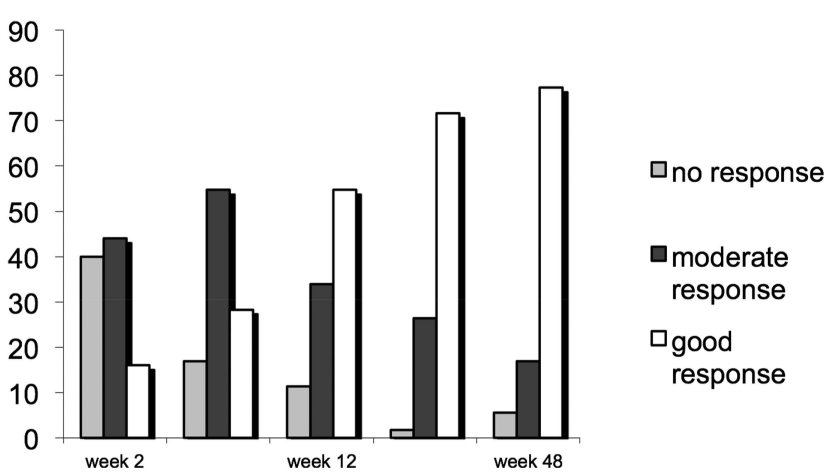

Figure I Percentage of patients showing changes in EULAR response during TCZ treatment. 
Table I Wrist Synovitis In The ITT Population

\begin{tabular}{|c|c|c|c|c|c|c|c|}
\hline & & Baseline & Week 2 & Week 4 & Week I2 & Week 24 & Week 48 \\
\hline RAMRIS & $\begin{array}{l}\text { No. of pts } \\
\text { Mean (SD) } \\
\text { Median }\end{array}$ & $\begin{array}{l}55 \\
5.78(2.72) \\
6.00\end{array}$ & $\begin{array}{l}45 \\
-0.44(1.03)^{*} \\
0.00\end{array}$ & $\begin{array}{l}49 \\
-0.88(1.56)^{\circ} \\
-1.00\end{array}$ & $\begin{array}{l}50 \\
-1.28(1.96)^{\#} \\
-1.00\end{array}$ & $\begin{array}{l}49 \\
-1.94(2.34)^{\#} \\
-2.00\end{array}$ & $\begin{array}{l}47 \\
-1.60(2.42)^{\#} \\
-2.00\end{array}$ \\
\hline RE & $\begin{array}{l}\text { No. of pts } \\
\text { Mean (SD) } \\
\text { Median }\end{array}$ & $\begin{array}{l}54 \\
99.25(57.85) \\
103.45\end{array}$ & $\begin{array}{l}44 \\
5.80(46.14) \\
3.00\end{array}$ & $\begin{array}{l}45 \\
-0.48(47.85) \\
-6.50\end{array}$ & $\begin{array}{l}49 \\
-9.27(50.07) \\
-8.00\end{array}$ & $\begin{array}{l}48 \\
-26.48(57.99)^{\circ} \\
-24.10\end{array}$ & $\begin{array}{l}45 \\
-19.74(74.08) \\
-20.40\end{array}$ \\
\hline REE & $\begin{array}{l}\text { No. of pts } \\
\text { Mean (SD) } \\
\text { Median }\end{array}$ & $\begin{array}{l}54 \\
1.19(1.04) \\
1.00\end{array}$ & $\begin{array}{l}44 \\
-0.04(1.11) \\
0.00\end{array}$ & $\begin{array}{l}45 \\
-0.10(0.86) \\
0.00\end{array}$ & $\begin{array}{l}49 \\
-0.48(0.96)^{*} \\
-0.20\end{array}$ & $\begin{array}{l}48 \\
-0.57(0.87)^{\circ} \\
-0.45\end{array}$ & $\begin{array}{l}45 \\
-0.66(1.24)^{\circ} \\
-0.30\end{array}$ \\
\hline
\end{tabular}

Notes: ${ }^{*} \mathrm{P}<0.005,{ }^{\circ} \mathrm{p}<0.01$, ${ }^{*} \mathrm{p}<0.001$ vs baseline in the ANOVA model.

Abbreviations: RAMRIS, Rheumatoid Arthritis MRI Score; RE, relative enhancement; REE, rate of early enhancement.

Table 2 MRI Parameters As Measured Using Dynamika ${ }^{\circledR}$ Software (ITT population)

\begin{tabular}{|c|c|c|c|c|c|c|c|}
\hline & & Baseline & Week 2 & Week 4 & Week I2 & Week 24 & Week 48 \\
\hline IRE & $\begin{array}{l}\text { No. of pts } \\
\text { Mean (SD) } \\
\text { Median }\end{array}$ & $\begin{array}{l}49 \\
0.005(0.004) \\
0.005\end{array}$ & $\begin{array}{l}39 \\
-0.000(0.003) \\
-0.000\end{array}$ & $\begin{array}{l}43 \\
-0.000(0.004) \\
-0.001\end{array}$ & $\begin{array}{l}43 \\
-0.001(0.004) \\
-0.002\end{array}$ & $\begin{array}{l}39 \\
-0.001(0.006) \\
-0.001\end{array}$ & $\begin{array}{l}32 \\
-0.002(0.004)^{\circ} \\
-0.002\end{array}$ \\
\hline ME & $\begin{array}{l}\text { No. of pts } \\
\text { Mean (SD) } \\
\text { Median }\end{array}$ & $\begin{array}{l}49 \\
1.606(0.422) \\
1.599\end{array}$ & $\begin{array}{l}39 \\
0.176(1.264) \\
0.027\end{array}$ & $\begin{array}{l}43 \\
-0.039(0.289) \\
0.005\end{array}$ & $\begin{array}{l}43 \\
-0.076(0.393) \\
-0.046\end{array}$ & $\begin{array}{l}39 \\
0.024(1.143)^{\circ} \\
-0.081\end{array}$ & $\begin{array}{l}32 \\
-0.177(0.416)^{\circ} \\
-0.112\end{array}$ \\
\hline Ntotal & $\begin{array}{l}\text { No. of pts } \\
\text { Mean (SD) } \\
\text { Median }\end{array}$ & $\begin{array}{l}48 \\
3155.7(1677.2) \\
3309.0\end{array}$ & $\begin{array}{l}38 \\
\mid 59.7(\mid 407.7) \\
-51.00\end{array}$ & $\begin{array}{l}42 \\
-544.4(\mid 251.4) \\
-437.0\end{array}$ & $\begin{array}{l}42 \\
-605.4(|54| .2) \\
-830.0\end{array}$ & $\begin{array}{l}38 \\
-560.6(1703.3) \\
-719.5\end{array}$ & $\begin{array}{l}31 \\
-974.2(1606.1)^{\circ} \\
-1108.0\end{array}$ \\
\hline Npersistent & $\begin{array}{l}\text { No. of pts } \\
\text { Mean (SD) } \\
\text { Median }\end{array}$ & $\begin{array}{l}49 \\
182.04(\mid 57.15) \\
132.0\end{array}$ & $\begin{array}{l}39 \\
-22.97(124.88) \\
0.00\end{array}$ & $\begin{array}{l}43 \\
-26.65(248.49) \\
-18.00\end{array}$ & $\begin{array}{l}43 \\
15.93(255.49) \\
-4.00\end{array}$ & $\begin{array}{l}39 \\
-12.46(\mid 53.01) \\
-21.00\end{array}$ & $\begin{array}{l}32 \\
-0.53(2 \mid 9.74) \\
5.00\end{array}$ \\
\hline Nplateau & $\begin{array}{l}\text { No. of pts } \\
\text { Mean (SD) } \\
\text { Median }\end{array}$ & $\begin{array}{l}49 \\
1839.6(994.1) \\
1769.0\end{array}$ & $\begin{array}{l}39 \\
135.4(936.6) \\
140.0\end{array}$ & $\begin{array}{l}43 \\
-183.8(855.9) \\
-161.0\end{array}$ & $\begin{array}{l}43 \\
-253.7(1054.6) \\
-205.0\end{array}$ & $\begin{array}{l}39 \\
-353.4(1136.0) \\
-509.0\end{array}$ & $\begin{array}{l}32 \\
-635.7(1019.1)^{*} \\
-676.0\end{array}$ \\
\hline Nwashout & $\begin{array}{l}\text { No. of pts } \\
\text { Mean (SD) } \\
\text { Median }\end{array}$ & $\begin{array}{l}49 \\
1167.2(783.2) \\
1036.0\end{array}$ & $\begin{array}{l}39 \\
10.0(721.7) \\
61.0\end{array}$ & $\begin{array}{l}43 \\
-349.3(708.8) \\
-178.0\end{array}$ & $\begin{array}{l}43 \\
-396.4(664.9)^{\circ} \\
-212.0\end{array}$ & $\begin{array}{l}39 \\
-280.2(852.6) \\
-110.0\end{array}$ & $\begin{array}{l}32 \\
-358.3(798.9)^{*} \\
-307.5\end{array}$ \\
\hline Ntotal*IRE & $\begin{array}{l}\text { No. of pts } \\
\text { Mean (SD) } \\
\text { Median }\end{array}$ & $\begin{array}{l}48 \\
6.01(5.93) \\
4.15\end{array}$ & $\begin{array}{l}38 \\
-0.05(5.32) \\
-0.03\end{array}$ & $\begin{array}{l}42 \\
-1.15(5.37) \\
-1.08\end{array}$ & $\begin{array}{l}42 \\
-2.56(5.35)^{*} \\
-1.77\end{array}$ & $\begin{array}{l}38 \\
-2.5 I(5.4 I)^{*} \\
-1.38\end{array}$ & $\begin{array}{l}31 \\
-4.84(6.13)^{\#} \\
-3.49\end{array}$ \\
\hline Ntotal*ME & $\begin{array}{l}\text { No. of pts } \\
\text { Mean (SD) } \\
\text { Median }\end{array}$ & $\begin{array}{l}48 \\
1882.4(1267.5) \\
1679.0\end{array}$ & $\begin{array}{l}38 \\
1009.9(6532.7) \\
-43.9\end{array}$ & $\begin{array}{l}42 \\
-431.3(1066.9) \\
-209.6\end{array}$ & $\begin{array}{l}42 \\
-535.8(1282.6) \\
-437.0\end{array}$ & $\begin{array}{l}38 \\
-597.1(1320.7)^{*} \\
-4 \mid 1.5\end{array}$ & $\begin{array}{l}31 \\
-793.6(1168.6)^{\#} \\
-761.5\end{array}$ \\
\hline
\end{tabular}

Notes: $* \mathrm{P}<0.005,{ }^{\circ} \mathrm{p}<0.01,{ }^{\#} \mathrm{p}<0.001$ vs baseline (repeated measure ANOVA).

Abbreviations: IRE, initial rate of enhancement; ME, maximal enhancement; Ntotal, total number of enhancing voxels; Nwashout, number of voxels with washout.

in a representative patient. There was no change from baseline to week 48 in the mean aggregate erosion score (mean change $0.36 \pm 4.17$ ), or the scores for the wrist (mean change $0.34 \pm 3.67$ ) or MCP joints (mean change $0.98 \pm 1.18$ ), and the number of bones with erosions at baseline $(8.07 \pm 4.71)$ did not change at end of study (mean change $-0.04 \pm 2.81$ ). Similarly, there were no radiographic changes in the hands from baseline to week 48 as evaluated by the TMSS (mean 


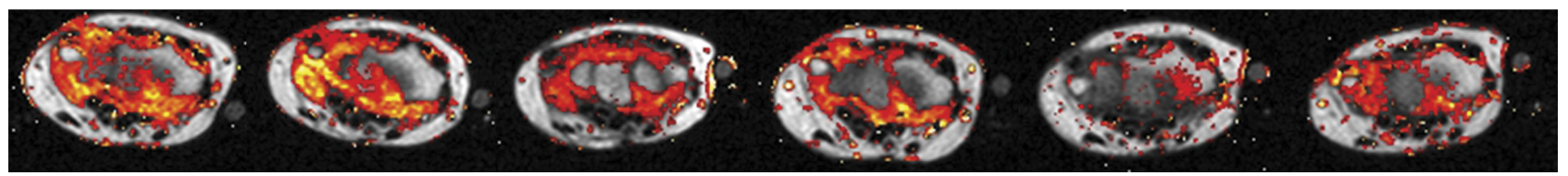

Figure 2 Changes in ME as evaluated by the Dynamika software in a representative patient. Note the progressive improvement in synovitis until week 24 and its worsening at week 48 , which corresponded to a slight and temporary clinical deterioration.

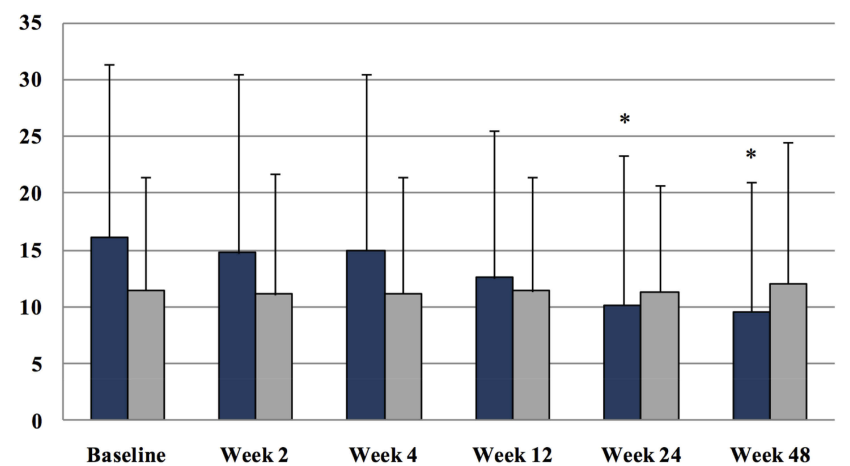

Figure 3 Bone marrow edema (blue) and erosion aggregate scores (light grey) at the different time points (ITT population). Mean values \pm SD. ${ }^{*} p<0.01$ vs baseline (repeated measure ANOVA).

change 1.46 \pm 5.66 ), or its component erosion score (mean change $0.31 \pm 1.07$ ) or joints synovial narrow (JSN) score (mean change $1.15 \pm 5.42$ ).

Fifty patients $(86.2 \%)$ experienced at least one treatment emergent adverse event (TEAE, AEs started at or after the first administration of the study treatment), mainly infections (39.7\%) and laboratory abnormalities (36.2\%). However, only two patients (3.4\%) discontinued the study prematurely because of AEs (erythematous rash, face edema and tachycardia in one patient, and herpes zoster in the second), although 27 (46.6\%) required TCZ dose modifications.

\section{Discussion}

This is the largest study in which the effect of TCZ was analyzed using contrast-enhanced MRI, showing that the drug is efficacious as early as two weeks after the start of treatment, although the number of patients was lower than that calculated for the defining the power of the study because of enrolment difficulties in some of the participating centres. There are only a few MRI studies evaluating TCZ treatment in RA patients. One low-field, extremitydedicated MRI study of a small number of patients refractory to anti-tumour necrosis factor (TNF) biological agents showed improvements in MRI indices after 44 weeks, but no clear short-term (20-week) response. ${ }^{8}$ Another study administered TCZ to 29 RA patients and evaluated its effects after two and five months using a $1.5 \mathrm{~T}$ machine: TCZ improved the patients' clinical and laboratory parameters, but there was no change in the MRI findings. ${ }^{7}$ The delayed or absent MRI effects may have been due to difficulties in clearly distinguishing bone erosion and $\mathrm{BME}$, the relatively large fields of view with a low spatial resolution (a heart coil was used in one study), the use of scores other than RAMRIS and, most importantly, the fact that MRI without contrast enhancement was used, which is less sensitive to treatment-induced changes in synovitis. Furthermore, the studies used STIR sequences to evaluate synovitis although they have been shown to be less sensitive than post-contrast sequences in this setting. ${ }^{19-20}$

Conaghan et al compared the efficacy of TCZ monotherapy and combined TCZ and DMARD treatment using extremity-dedicated MRI and the same machine as that used in our study. TCZ alone improved synovitis and osteitis as early as two weeks after the start of the study,

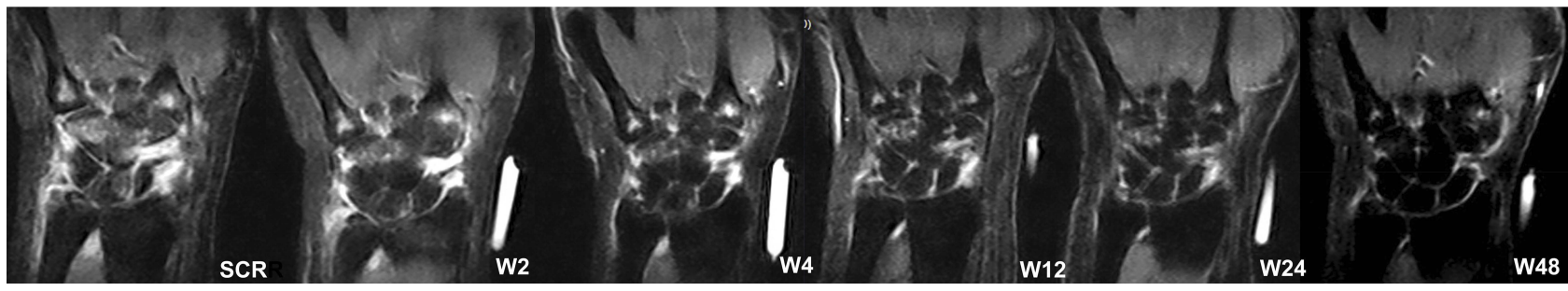

Figure 4 Changes in bone marrow edema (BME) as evaluated by means of STIR sequences in an individual patient. Note the progressive improvement in BME, which was paralleled by a decrease in the corresponding RAMRIS value from 42 at baseline to 18 after 48 weeks. The STIR images also showed an improvement in synovitis during the same period. 
whereas the combined treatment showed no significant efficacy after 52 months. ${ }^{9}$

On the contrary, we found that TCZ rapidly decreased synovitis as evaluated by means of contrast-enhanced MRI in a cohort of patients concomitantly treated with DMARDs. There is no apparent reason why TCZ should be more effective on MRI findings when given alone rather than in combination with DMARDs, but the differences between our findings and those of Conaghan et al may be due to our larger patient population, which probably allowed statistical significance to be reached. ${ }^{9}$

We observed a statistically significant decrease in the RAMRIS for wrist synovitis after only two weeks of TCZ treatment, which was maintained until the end of the study, thus paralleling the rapid and continuous clinical efficacy of TCZ. The drug is therefore not acting on the composite indices of disease activity by only modifying inflammation markers, but also has a profound effect on synovitis. The quantitative assessment of the degree of synovitis by means of dynamic, gadolinium-enhanced MRI of the wrist showed statistically significant improvements in REE from baseline to weeks 12, 24 and 48, and in RE to week 24 . There were also statistically significant improvements from baseline to week 48 in the MRI parameters measured using Dynamika ${ }^{\circledR}$ software, a system that incorporates efficient data processing and analysis techniques in order to ensure significantly better data quality. ${ }^{15,16}$ Contrary to our expectations, the semi-quantitative RAMRIS for synovitis was apparently more sensitive to change than the theoretically more objective (because continuous and less observer-dependent) DCE-MRI, something that cannot be explained on the basis of the interpretation of the RAMRIS readers because they were blinded to the timing of the images, an approach which was deemed more appropriate because of the absence of a control group.

It has been shown that the multi-planar nature of MRI makes it more sensitive than conventional radiography in detecting the progression of bone erosion, and it has also been found that there is a high level of agreement between low-field extremity and high-field conventional MRI in detecting bone erosions and synovitis. ${ }^{21,23}$

Previous MRI studies of the progression of bone erosions in RA have shown that, despite its clinical efficacy, one year of treatment with MTX was followed by an increase in the number of patients with erosions and in the number of erosions themselves. ${ }^{24}$ We did not find any radiographic or MRI evidence of the progression of bone erosions during the 48 weeks of TCZ therapy, a finding that is in line with that of Conaghan et al. ${ }^{9}$

MRI-detected BME is considered an interim phase between synovitis and bone erosion, and seems to be a strong predictor of subsequent radiographic progression in patients with early RA. ${ }^{24}$ Although low-field MRI is only moderately sensitive in detecting $\mathrm{BME},{ }^{22}$ we found that TCZ treatment was associated with a decrease in wrist and MCP BME that became significant after 24 weeks. This result is in keeping with the study of Bensaoud et al, who also noted a significant decrease of the RAMRIS BME score after 6 months of TCZ treatment but constrasts with that of Hirota et al, who noted it only after 52 weeks. ${ }^{10,11}$

However, in Bensaoud et al study, only two MRIs were performed at baseline and at 6 months, whereas in our study MRI follow-up was done regularly on six occasions. As a result we can state that the minimum time necessary for BME to improve during TCZ treatment is between 12 and 24 weeks. Our finding that one year's treatment with TCZ significantly reduced synovitis and edema in patients with moderate to severe active RA, and the fact that there was no evidence of any further progression of bone erosions, support the finding of recent clinical trials that TCZ is a disease-modifying agent that limits joint damage regardless of its effects on disease activity. ${ }^{25}$

In line with previous findings, we found that the combination of TCZ and DMARDs was rapidly effective in inducing rapid and sustained improvements in the signs and symptoms of RA. ${ }^{4}$

The marked decrease from baseline in mean DAS-28 CRP (and its components) that was evident after just two weeks of treatment was maintained for the 48 weeks of the study.

The limitations of this study are the relatively small number of patients and the lack of a control group. Its strengths are the large number of images recorded over one year, the use of an intravenous contrast medium in order to visualise synovitis, the use of DCE-MRI, and the fact that the same type of machine was used in the different study centres. This fact, which is uncommon in multicentre MRI trials, allowed the meticulous standardisation of the procedures and of the interpretation of the results.

In conclusion, the results of this study of a population of Italian patients with moderate to severe active RA not responding to DMARD therapy show that combined treatment with TCZ $8 \mathrm{mg} / \mathrm{kg}$ and DMARDs is highly effective in controlling MRI wrist synovitis and bone marrow edema, clinical parameters, and erosive progression. Further doubleblind and placebo-controlled trials are needed to investigate 
the effect of TCZ on the different parameters of contrastenhanced MRI synovitis in more detail.

\section{Ethics Statement}

The study was conducted according to the Declaration of Helsinki. The protocol was reviewed and approved by each centre's ethics committee, reflecting national requirements for study conduct approval. All patients provided written informed consent. The authors cannot share individual deidentified participant data, according to the sponsor rule.

\section{Acknowledgements}

The study was carried out with the contribution of the following investigators and study sites:

Bombardieri S (Rheumatology Unit, Santa Chiara Hospital, University of Pisa, Italy),

Cimmino MA (Research Laboratory and Academic Division of Clinical Rheumatology, DIMI, University of Genoa, Italy), Giacomelli R (Rheumatology Unit, University of L'Aquila, Italy),

Iagnocco A (Academic Rheumatology Centre, Università degli Studi di Torino, Turin, Italy), Montecucco CM (Department of Rheumatology, S. Matteo Hospital, Pavia, Italy), Punzi L (Rheumatology Unit, University of Padua, Italy), Sarzi Puttini P (Rheumatology Unit, L. Sacco University Hospital, Milan, Italy), Scarpa R (Rheumatology Unit, Department of Clinical and Experimental Medicine, Federico II University, Naples, Italy), Triolo G (Division of Rheumatology, P. Giaccone Hospital, Palermo, Italy), Sinigaglia L (Rheumatology Unit, G. Pini Hospital, Milan, Italy),

Govoni M (Section of Rheumatology, University of Ferrara, Italy). The authors would like to thank Quintiles S.p.A. (Milan, Italy) for contributing to the project management, data analysis, and writing of this article. The sponsor, F. Hoffmann-La Roche, designed the trials in consultation with members of the ACTRACE steering committee. Data were collected by the site investigators and were analyzed by the sponsor. All the authors vouch for the accuracy and completeness of the data and for the fidelity of the trial to the protocol. A subgroup of authors drafted the manuscript, and Roche and all the authors reviewed and approved the final version and made the decision to submit the manuscript for publication. The authors would like to thank Chiara Donati (Roche S.p. A.) for reviewing the paper.

\section{Author Contributions}

All authors contributed to data analysis, drafting and revising the article, gave final approval of the version to be published, and agree to be accountable for all aspects of the work.

\section{Disclosure}

MAC has received grant support, consultation fees and/or speaker honoraria from Abbvie, Bristol-Myers Squibb, Janssen, Menarini, Novartis, Pfizer, Roche, and UCB. SB is member of the advisory board. AI has received grant support and/or honoraria from Abbvie, GE, Bristol-Myers Squibb, and Merck, Sharp and Dhome. LS has received speaker honoraria from Abbvie, Amgen, Ely Lilly, Roche and UCB. FDB has received unrestricted research grants from Abbvie, Bristol-Myers Squibb, Novartis, Novimmune, Pfizer, Roche, and Sobi. PSP has received consulting fees, speaker fees and/or honoraria from Abbvie, BMS, MSD, Pfizer, and Roche. The authors report no other conflicts of interest in this work.

\section{References}

1. Baker JF, Ostergaard M, Emery P, et al. Early MRI measures independently predict 1-year and 2-year radiographic progression in rheumatoid arthritis: secondary analysis from a large clinical trial. Ann Rheum Dis. 2013. doi:10.1136/annrheumdis-2013-203444

2. Keller ET, Wanagat J, Ershler WB. Molecular and cellular biology of interleukin-6 and its receptor. Front Biosci. 1996;1:340-357. doi:10.2741/A136

3. Smolen JS, Beaulieu A, Rubbert-Roth A, et al. Effect of interleukin-6 receptor inhibition with tocilizumab in patients with rheumatoid arthritis (OPTION study): a double-blind, placebo-controlled, randomised trial. Lancet. 2008;371:987-997. doi:10.1016/S01406736(08)60453-5

4. Fleischmann RM, Halland AM, Brzosko M, et al. Tocilizumab inhibits structural joint damage and improves physical function in patients with rheumatoid arthritis and inadequate responses to methotrexate: LITHE study 2-year results. J Rheumatol. 2013;40:113-126. doi:10.3899/ jrheum. 120447

5. Jones G, Sebba A, Gu J, et al. Comparison of TCZ monotherapy versus methotrexate monotherapy in patients with moderate to severe rheumatoid arthritis: the AMBITION study. Ann Rheum Dis. 2010;69:88-96. doi:10.1136/ard.2008.105197

6. Jones G, Panova E. New insights and long-term safety of tocilizumab in rheumatoid arthritis. Ther Adv Musculoskelet Dis. 2018;10(10):195199. Published 2018. doi:10.1177/1759720X18798462

7. Kamishima T, Tanimura K, Shimizu M, Matsuhashi M, Fukae J, Kon Y. Monitoring anti-interleukin 6-receptor antibody treatment for rheumatoid arthritis by quantitative magnetic resonance imaging of the hand and power Doppler ultrasonography of the finger. Skel Radiol. 2011;40:745-755. doi:10.1007/s00256-010-1064-4

8. Suzuki T, Horikoshi M, Sugihara M, et al. Therapeutic efficacy of tocilizumab in patients with rheumatoid arthritis refractory to antitumor-necrosis-factor inhibitors: 1 year follow-up with low-field extremity MRI. Mod Rheumatol. 2013;23:782-787. doi:10.3109/s10165012-0746-2 
9. Conaghan PG, Peterfy C, Olech E, et al. The effects of tocilizumab on osteitis, synovitis and erosion progression in rheumatoid arthritis: results from the ACT-RAY MRI substudy. Ann Rheum Dis. 2014;73:810-816. doi:10.1136/annrheumdis-2013-204762

10. Bensaoud N, Rostom S, Bahiri R, Hajjaj-Hassouni N. Efficacy of tocilizumab on MRI-determined bone oedema in rheumatoid arthritis Clin Rheumatol. 2015;34:1031-1037. doi:10.1007/s10067-015-2934-x

11. Hirota T, Suzuki T, Ogishima H, et al. Evaluation of changes in magnetic resonance images following 24 and 52 weeks of treatment of rheumatoid arthritis with infliximab, tocilizumab, or abatacept. Mod Rheumatol. 2016;26:29-35. doi:10.3109/14397595.2015.1069471

12. Ejbjerg B, McQueen F, Lassere M, et al. The EULAR-OMERACT rheumatoid arthritis MRI reference image atlas: the wrist joint Ann Rheum Dis. 2005;64 Suppl 1(Suppl1):i23-i47. doi:10.1136/ ard.2004.031823

13. Woodworth TG, Morgacheva O, Pimienta OL, Troum OM, Ranganath VK, Furst DE. Examining the validity of the rheumatoid arthritis magnetic resonance imaging score according to the OMERACT filter-a systematic literature review. Rheumatology (Oxford). 2017;56(7):1177-1188. doi:10.1093/rheumatology/kew445

14. Grosse U, Henes J, Grözinger G, et al. Anatomic-functional (perfusion-based) magnetic resonance imaging follow-up in patients with rheumatoid arthritis treated with anti-interleukin 6 antibodies: a comparison with clinical scores and serologic data. J Comput Assist Tomogr. 2015;39:75-82. doi:10.1097/RCT.0000000000000152

15. Boesen M, Kubassova O, Bouert R, et al. Correlation between computer-aided dynamic, gadolinium-enhanced MRI assessment of synovitis and semiquantitative synovitis and bone marrow oedema scores of the wrist in patients with rheumatoid arthritis - a cohort study. Rheumatology (Oxford). 2012;51:134-143. doi:10.1093/rheumatology/ker220

16. Kubassova O, Boesen M, Cimmino MA, Bliddal H. A computeraided detection system for rheumatoid arthritis MRI data interpretation and quantification of synovial activity. Eur $J$ Radiol. 2010;74:67-72. doi:10.1016/j.ejrad.2009.04.010

17. Arnett FC, Edworthy SM, Bloch DA, et al. The American Rheumatism Association 1987 revised criteria for the classification of rheumatoid arthritis. Arthritis Rheum. 1988;31:315-324. doi:10.1002/(ISSN)1529-0131
18. Cimmino MA, Innocenti S, Livrone F, Magnaguagno F, Silvestri E, Garlaschi G. Dynamic gadolinium-enhanced magnetic resonance imaging of the wrist in patients with rheumatoid arthritis can discriminate active from inactive disease. Arthritis Rheum. 2003;48:1207-1213. doi:10.1002/(ISSN)1529-0131

19. van Gestel AM, Haagsma CJ, van Riel PL. Validation of rheumatoid arthritis improvement criteria that include simplified joint counts. Arthritis Rheum. 1998;41:1845-1850. doi:10.1002/1529-0131(199810)41:10 $<1845::$ AID-ART17>3.0.CO;2-K

20. Ostergaard M, Conaghan PG, O’Connor P, et al. Reducing invasiveness, duration, and cost of magnetic resonance imaging in rheumatoid arthritis by omitting intravenous contrast injection Does it change the assessment of inflammatory and destructive joint changes by the OMERACT RAMRIS?. J Rheumatol. 2009;36:1806-1810. doi:10.3899/jrheum.090350

21. Duer-Jensen A, Ejbjerg B, Albrecht-Beste E, et al. Does low-field dedicated extremity MRI (E-MRI) reliably detect bone erosions in rheumatoid arthritis? A comparison of two different E-MRI units and conventional radiography with high-resolution CT scanning. Ann Rheum Dis. 2009;68:1296-1302. doi:10.1136/ard.2008.093591

22. Ejbjerg BJ, Narvestad E, Jacobsen S, Thomsen HS, Østergaard M. Optimised, low cost, low field dedicated extremity MRI is highly specific and sensitive for synovitis and bone erosions in rheumatoid arthritis wrist and finger joints: comparison with conventional high field MRI and radiography. Ann Rheum Dis. 2005;64:1280-1287. doi:10.1136/ard.2004.029850

23. Lindegaard HM, Vallø J, Hørslev-Petersen K, Junker P, Østergaard M. Low-cost, low-field dedicated extremity magnetic resonance imaging in early rheumatoid arthritis: a 1-year follow-up study. Ann Rheum Dis. 2006;65:1208-1212. doi:10.1136/ard.2005.049213

24. Hetland ML, Ejbjerg B, Hørslev-Petersen K, et al. MRI bone oedema is the strongest predictor of subsequent radiographic progression in early rheumatoid arthritis. Results from a 2-year randomised controlled trial (CIMESTRA). Ann Rheum Dis. 2009;68:384-390. doi:10.1136/ard.2008.088245

25. Smolen JS, Avila JC, Aletaha D. Tocilizumab inhibits progression of joint damage in rheumatoid arthritis irrespective of its anti-inflammatory effects: disassociation of the link between inflammation and destruction. Ann Rheum Dis. 2012;71:687-693. doi:10.1136/ annrheumdis-2011-200395

\section{Publish your work in this journal}

Biologics: Targets and Therapy is an international, peer-reviewed journal focusing on the patho-physiological rationale for and clinical application of Biologic agents in the management of autoimmune diseases, cancers or other pathologies where a molecular target can be identified. This journal is indexed on PubMed Central, CAS, EMBase,
Scopus and the Elsevier Bibliographic databases. The manuscript management system is completely online and includes a very quick and fair peer-review system, which is all easy to use. Visit $\mathrm{http}: / /$ www.dovepress.com/testimonials.php to read real quotes from published authors. 